\title{
Lucia Bedarida Servadio: A Life Beyond Limits. A Female Italian Jewish Scientist in Tangier
}

\author{
Cristina Bettin \\ Ben Gurion University of the Negev, Negev, Israel
}

\begin{abstract}
Italian Jewish women in the early 20th century, and, their struggle with their Italian national identity, culture, and, Jewish heritage is a topic that has not been yet sufficiently studied, in particular the one regarding Italian Jewish women in sciences and their contribution to the Italian culture. With the exception of a few memoirs, as well a book recently published in Italian, who depicted shortly the life of some of these women, to this day, there is a paucity of publications about it, with the result that, there is little knowledge about them and their "pioneering spirit" and "modernism”. Thus, this article aims to spread light on one of these extraordinary women: the tubiba (Arabic name for doctor) Lucia Bedarida Servadio. In analyzing Lucia’s life through her memoirs, writings, and, unpublished documents, such as private letters that she wrote to her friends and family, I will show the impact that this "avant-garde”, and, still quite unknown women had in the Italian society. Above all, the legacy that she left as a "messenger" of peace, in dedicating her whole life, to help the "others", despite their colors, race and religion, like she did in Morocco from 1940 until 1981.
\end{abstract}

Keywords: Italian Jewish women, memoirs, Jewish education, Italian national identity, Jewish heritage, racial discrimination

Lucia Servadio born in Ancona ${ }^{1}$ in 1900 into a Jewish family belongs to the upper middle class. Her father $^{2}$ was a businessman that he used to represent big foreign corporations and negotiated contracts for them, while her mother, Gemma Vitale Servadio ${ }^{3}$ was taking care of the household and children.

Lucia, was the first born, and, the only girl of five children: Luciano, Lucio, Luxardo, Luchino, that, like her, were all given first named based on the Italian word "luce" (light) to symbolize her family's commitment to justice and freedom. ${ }^{4}$

Lucia family's was very patriotic, so much so, that her grandparents named their children Cavour (her father), in honor of Camillo Cavour, ${ }^{5}$ and Italia, (her aunt) to celebrate the reunification of the Marche (the

Cristina Bettin, Ph.D., Senior Lecturer and Researcher, Department of Foreign Literatures \& Linguistics, Ben-Gurion University of the Negev.

Correspondence concerning this article should be addressed to Cristina M. Bettin, P.O.B. 653, Beer-Sheva 84105, Israel.

1 Ancona is a city in northeast of Italy.

2 Lucia's father was born in Ancona in 1862 and died in Rome in 1924.

${ }^{3}$ Lucia's mother was born in Turin in 1878 and died in Auschwitz in 1944.

4 After Jewish Emancipation, and Italy's unification, many Jews gave to their children Italian names. The most common were names such as Italia, Vittorio or Emanuele (name of the Savoy dynasty, that signed the Edict of Jewish Emancipation).

${ }^{5}$ Camillo Cavour (1810-1861), was a statesman and a leading figure in the Italian independence movement. He was the founder of the original Liberal Party and Prime Minister of the Kingdom of Piedmont and Sardinia. After the beginning of Italy's unification, in 1861, Cavour became the first Prime Minister. But his duty last only for a short period, because he died after only three months, without seeing the completely unification of Italy. 
region where the family lived) to the Italian Kingdom. ${ }^{6}$

Lucia born in a time when the Italian Jewish population was already emancipated, with, as she recalled in her memoirs:

The same rights and duties of any Italian citizens. With no ghettos, no restrictions, no quotas. We lived where we liked, we traveled as we wished, we chose the professions that we wanted. My brothers and I attended public school and later the university. Our family frequented non-Jewish friends, and we were accepted as their peers. ${ }^{7}$

Lucia's family was completed integrated into the Italian society, and, as she used to say "completely immersed in Italian culture". Servadio family, like the majority of the Italian Jewish families of the end of the 19th and beginning of the 20th century, had a strong Italian identity. And, like the rest of the Italian population they conducted the same lifestyle. ${ }^{8}$

The process of Jewish integration in Italy began with the Emancipation, which started in $1848^{9}$ and continued with Italy's unification. ${ }^{10}$

From the time of the unification, Jews participated actively in the political and public life of the country ${ }^{11}$ without differentiation with the rest of the Italian population.

\footnotetext{
${ }^{6}$ Cavour and Italia's parents died when the children were young and therefore were brought up by an aunt and her husband. So, Lucia never met her grandparents.

${ }^{7}$ Bedarida Servadio Lucia, "Reflection on an Italian Jewish Life", The Most Ancient of minorities—-the Jews of Italy (Westport, 2002), 353.

${ }^{8}$ It is possible to find the same feelings of belongings to the Italian nation and equality in many Italian Jewish memoirs and biographies. See, Bettin Cristina, “A question of identities: Jewish Italian immigrants in New York, during and after War World II ”, Cultural and Religious Studies 4, n. 4 (2016): 220.

${ }^{9}$ On March 29, 1848, Carlo Alberto di Savoia King of Piedmont signed the Edict of Emancipation, extending civil rights to the non-Catholics, including all the Jews who were under his domain. However, until Italy's unification (1861-1870), each region has his own policy toward the Jews. For example, the territories of the Italian Peninsula, that were under foreign domination, such as Lombardo-Veneto and Trieste (under Austrian rule), or in the Papal States etc. the Jews' conditions were less good.

${ }^{10}$ The unification of Italy, known also as Risorgimento (Revival), was the political movement that aimed to unify Italy into a single nation. Until the 19th century, Italy was divided into different regions, each with its own customs, culture, dialect (the local spoken language) and political administration. Italy's unification started in the 19th century, and, was almost completed in 1871, when Rome become capital of the Kingdom of Italy. Almost completed, and, not totally, because many Italians of the north east of Italy, especially those from the cities of Trieste, Gorizia and the surroundings area, were still outside the border of the new Italian nation. Only after War World I, Trieste and Gorizia will became part of Italy.

11 The most important Jew in Italian public life during the Risorgimento was Isac Artom, who served as Camillo Cavour's private secretary and chief secretary in the Italian Foreign Office and later, in 1876, as senator. In 1861, Giuseppe Finzi, together with two others Jews, was elected to serve in the first Italian Parliament, and in 1874 eleven Jews served as deputies. In 1891, Luigi Luzzati, a member of a prominent and patriotic Venetian Jewish family, served as Minister of Finance until 1892, from 1896 to 1898, and again from 1903 to 1906. From 1900 to 1903, another Jew, Leone Wollemberg, held the same position. In 1910, Luzzati was appointed Prime Minister. Other Jews, too, attained positions of power: in 1890, an irredentist journalist from Trieste, Salvatore Barzilai, the "deputato di Trieste al Parlamento Italiano" (the member of the Parliament of Trieste to the Italian Parliament), was elected to the Chamber of Deputies, where he remained for eight terms, serving in the Cabinet before and during World War I. He was a member of the Italian delegation to the Peace Conference at Versailles after the war. Treves and Modigliani served as socialist deputies for many years before, during, and after World War I. In 1888, Giuseppe Ottolenghi was elected senator. In 1902, he was appointed Italy’s first Jewish general. He was senator and later Minister of War during 1902-1903, while the Venetian Gabriele Pincherle was honorary president of the Council of State. In 1907, Ernesto Nathan was elected mayor of Rome. Leopoldo Franchetti served as a conservative senator for many years before committing suicide in despair after the Italian debacle of Caporetto. Sidney Sonnino, who was born a Jew in Pisa in 1847, but converted to Protestantism, served as Finance Minister and later as Foreign Minister. In 1906, and again from 1908 to 1910, he held the position of Prime Minister. Lodovico Mortara was Minister of Justice and Religious Cults from June 1919 to May 1920. These men were the best-known Jewish politicians, but there were many others. According to the historian Guido Bedarida, there were twenty-four Jewish senators in 1919. In 1923, the number rose to twenty-six, out of a total of 406 (about 5\%), and in 1927, of a total of 352 senators, seventeen were Jewish. When, at the beginning of 1919, Benito Mussolini, who was a former socialist journalist and former director of the socialist newspaper Avanti, founded the Fascist Party, he had Jewish support. Bettin, Cristina, Italian Jews from Emancipation to Racial Laws, (New York, 2010): 30-31.
} 
A factor that explains the swift integration of Jews into Italian society following their emancipation is the character of the Italian Jewish community itself: Italian Jews were not foreigners. They looked, dressed, and spoke like everyone else. And above all, they were educated.

Throughout the centuries, education has been one of the central axes of Jewish life. ${ }^{12}$

Jewish literacy characterized nearly all Italian communities (with the exception of the Roman ghetto $)^{13}$, and remained an advantage over the Gentile population long after the barriers of the ghetto were eliminated. In 1861, 64.5\% of the total population in Italy was illiterate, while the level of illiteracy among the Jews reached only $5.8 \% .{ }^{14}$ The literacy statistics included Jewish women.

In 1901, 92.5\% of Jewish girls between the ages of six and 14 could read and write, compared to $57 \%$ of the general Italian population. In the same year, $18.7 \%$ of Italian Jews belonged to the liberal professions, mainly law and medicine, or were employed as civil servants, compared to $6.4 \%$ of the remainder of the population. In 1919, of a total of 965 university professors, 61 (6.3\%) were Jewish.

The fact that Jews were well educated explains why they attained high positions in many fields from the time of their emancipation, not only in Italy, but in other countries as well.

In short, a bourgeois Jews at the end of the 19th and the beginning of the 20th century conducted themselves outside of his own home in the same manner as gentiles belonging to the same social class. Their ways of life were the same; both Jew and gentile lived in comfortable homes and employed nursemaids and servants. Their wives looked after their homes, went to the theatre and to concerts, and led active cultural lives; the children of the household received dancing lessons at home, studied piano and learned to speak French and German.

Such as Lucia did. Lucia’s mother, Gemma Vitale and grandmother Sara Nina Levi, that both died in Auschwitz in 1944, they didn't pursued an academic carrier, like Lucia, but they were well educated women.

They spoke Italian well and read a lot. They did not speak Hebrew, although Nina, Lucia's grandmother, would include some Hebrew words in her sentences.

However, both they know to read their prayers in Hebrew, even if, as Mirella, Lucia's daughter told me, ${ }^{15}$ she has some doubt that they did understand anything.

In re-calling her childhood, Mirella remembered that her grandmother Gemma, knew French quite well

\footnotetext{
12 The study of the Torah and the Holy books, which require the skills of reading and writing, has always been a mainstay of Jewish life. Schools has been created since the establishment of the first ghetto (Venice, 1516), and, every ghetto had its own school. Generally, the schools were attached to the synagogue, and open to boys and girls. The schools, were not private and fees were covered by voluntary contribution. Children from disadvantage families received also free meals, clothing and footwear. In some communities, there was also a kind of kindergarten where children up to the age three were taught to read and write. At the age of five, the children were enrolled in the Talmud Torah (religious school).

${ }^{13}$ Roman Ghetto was in the Papal States, and, was one of the poorest among all the ghettos. Segregated, since 1555 by the Pope Paolo IV (throughout his Bull, Cum Nimis Absurdum) Jews were living in a walled area of the city and regulated with strong restrictions almost in every aspect of their life. The only permitted work was to sell and repairs secondhand clothes. "They were forced to attend weekly sermons meant to convert them to the Catholicism. Indeed, it was a form of popular entertainment for the rabble to jeer and throw objects as they watched the Jews file off to Church. The Jews were forced to participate in public foot races at carnival time, a practice ended only when the community agreed to pay a tribute of 300 scudi to the Pope to be delivered each year in the capitol above the old Roman forum. With the crowning of each new Pope, elders of the Jewish community were compelled to pay tribute to the pontiff, kissing his foot before the symbol of their humiliation, the Arch of Titus". See, Stille Alexander,” The Double Bind of Italian Jews: Acceptance and Assimilation”, in Jews in Italy under Fascist and Nazi Rule 1922-1945, (New York: 2005), 24.

14 See, Bedarida Guido, Ebrei D’Italia ( Livorno: 1949), 92.

15 Since 2009, I interviewed many times Mirella Bedarida Shapiro, regarding her mother and family. Born in Italy, in Turin, in 1927, Mirella is the second daughter of Lucia, after Paola, born in 1924 and the last one Adria that was born in 1933. Like her sisters, Mirella lives in the United States.
} 
and wanted that all the Lucia's daughters learn the language. So she gave them books in French and sometime wrote to them letters to made them practice. The something happened with the study of English language.

Gemma, was an excellent piano player and had music soirees. She was very social, and, always had a lot of friends both Jewish and Catholics. She, like all the other members of the family, was secular, the house was not kosher $^{16}$, however, always, like also Lucia did they celebrated Jewish holidays, by going to the synagogue and having special meals.

Lucia' grandmother, Nina Vitale, she had, like all the Bedarida women, included Lucia's daughter, in particular Mirella, the "family trait" of wanting to live life fully. A thirsty for knowledge never ended.

She went to visit friends, to lectures, she wanted to keep up with that was going on in the world. Because as she used to say, even though she was already in her 80s "you are never too old, to learn something new".

Growing up with these type of women, influenced a lot Lucia, and shaped her character in making her a very special person.

Lucia was the first born and the only girl of five children, and, therefore was spoiled by her father and brothers. She had a very happy childhood and adolescence. She was very bright and good in school, in fact, she finished high school at 16 and obtained her medical degree with summa cum laude at the age of 22. In becoming in this way the youngest physician was in Italy.

Becoming a female doctor in these years, was quite uncommon for a woman because, as Lucia said in one of her talks in the United States in the early 1990s, "It was the deep rooted opinion of the times that only certain types of work, such as housework and child caring, were appropriate for what was called then the 'weaker sex'.,"17

Thing, that Lucia, as her life can show us, never accepted. And her immense curiosity, knowledge and open minded, that characterize her personality and intellect, made her a modern woman that broke many prejudices, in giving her the opportunity, like she said in one of her last interviews to always lived life to full, despite all the difficulties... and accomplished the things that really wanted ... ${ }^{18}$

At the beginning when she finished High School, Lucia was not completely sure about what to study, she knew that she has to pursue college studies, because, as her father always told her "she had to give the good example to her young brothers". However, medicine was not yet completely into her picture. Even if, perhaps without even knowing she was already "attract” by medicine and science, in fact, when her mother Gemma was volunteer nurse during World War I in the Military Hospital in Ancona, the city where they lived, Lucia used to ask her several questions about her experience, anxious to learn about the doctors' activities, as well the state of mind and body of those young men who, once past the danger of death, were trying to make a comeback entrusting their lives to the care of doctors and nurses. ${ }^{19}$

However, did not take her too much time to decide, in fact, after a short while after a visited to the Anatomy Institute of Turin and having looked at the histological slice under a microscope, and having listened

\footnotetext{
${ }^{16}$ Kosher is the permitted food according to Jewish Law.

${ }^{17}$ Quotation from an unpublished paper, that Lucia gave in the early 1990s in a conference organized by NIDO on Women and Medicine in New York Metropolitan area. This paper was given to the author by her daughter Mirella Bedarida Shapiro, in 2011, p. 1.

18 See, (July 24, 2000) Around the Jewish World: Woman's Life Mirrors Century of Struggles Successes, in www.jta.org/2000/07/24, JTA archive, 1.

${ }^{19}$ Quotation from an unpublished paper, that Lucia gave in the early 1990s in a conference organized by NIDO on Women and Medicine in New York Metropolitan area. This paper was given to the author by her daughter Mirella Bedarida Shapiro, in 2011, p. 1.
} 
to a young assistant describe it, she has, as she said in her last interview in 2006: a revelation.

I know then that the study of medicine was the career path I wanted to follow. I must say that during my 65 years of practice in the medical field, I have never regretted it; to this day, I proclaim that if there was a future life and I were to regain all my physical and intellectual capacities, I would choose medicine all over again.... This calling I heard, this influence on my feminine spirit to cure those who suffer, must have been very strong in that moment because many young lives were being broken and many other were exposed to incredible suffering. ${ }^{20}$

Lucia in fact, as we can read in the tribute that she wrote in honor of her friend, the Jewish doctor, Gemma Barzilai, ${ }^{21}$ that during War World II went back to Italy from the States, (where she fled as a consequences of the racial laws) as an Officer of the American Army, strongly believed that: the fact that women physicians worked with the Army on the battlefield, proves that women's physical and spiritual make-up allows them to withstand the perils and hardships of war, despite its risk, horrors and terrifying scenes. ${ }^{22}$

Nowadays, this fact is recognized and accepted everywhere, to the point that women regularly enter military schools, and in Israel military service is compulsory for women as well, but at Lucia's time, this fact was very rare.

In 1923, Lucia got married in Rome, with the doctor Nino Vittorio Bedarida. Born in 1889 into a Jewish family in Nizza Monferrato in Piedmont, Nino Vittorio Bedarida became a doctor in 1916. Like most Italian Jews of the time, he was very patriotic and nationalistic and from 1916 to 1918, he volunteered in World War I as an officer ${ }^{23}$ and field doctor.

Like Servadio's family, also the Bedarida were wealthy. Giuseppe Bedarida ${ }^{24}$, Nino's father, had a bank in Nizza (Bank of Bedarida's Brothers), and, in Turin a factory that manufactured enamel pots and pans.

After their marriage, the couple went to live in Turin, where Nino was working in the local hospital as a surgeon, and Lucia, due to the frame of mind of the times (which incidentally was then also mine) ${ }^{25}$, she pursued her medical activities mainly as a function of her surgeon research scientist husband, without any sense of envy or jealousy, because was he that was supposed to be successful in his carrier, not her.

That is why he helped him a lot in his laboratory experiment, library research, and surgery. However, Nino admired her very much, especially her intelligence and medical acuity, and, when he was not sure of a diagnosis always called her in to examine the patient and to give him, her opinion.

He also supported Lucia's decision, to spend a year in Rome for a specialization in radiology and being at home in Turin with their daughters.

In 1930, Lucia and her family moved to Vasto, a small town in Abruzzo, where Nino was invited to assume the position of Chief Surgeon at the local hospital.

The Bedarida was the only Jewish family of the town. Therefore, all their friends and colleagues were Catholics. The hospital where Nino and Lucia (who continued to work with him) worked was managed by nuns, but as Lucia said many times she never felt any discrimination at all, on the contrary she as well her husband, were very welcome and respected by everybody. Like all the rest of the Italian population, Lucia and Nino were

${ }^{20}$ See, Fincato Olivia and D’Agostin Renato, Un giorno con Lucia, (Italy: 2007), 28.

${ }^{21}$ Barzilai Gemma was a Jew from Trieste, which studied medicine in Rome with Lucia.

${ }^{22}$ This unpublished letter was gave to the author by Mirella Bedarida Shapiro, Lucia’s daughter, in New York in 2011.

${ }^{23}$ Nino Vittorio Bedarida was captain in the Alpine division.

24 Bedarida Giuseppe, was born in Nizza Monferrato in 1858 and died in Turin in 1921.

${ }^{25}$ Quotation from an unpublished paper, that Lucia gave in the early 1990s in a conference organized by NIDO on Women and Medicine in New York Metropolitan area. This paper was given to the author by her daughter Mirella Bedarida Shapiro, in 2011, p. 3. 
obliged to belong to the Fascist Party, where both received high-ranking positions, Nino as the Chief Medical Examiner of the Fascist Militia, and, Lucia as secretary of the women's fascist party of Vasto. This, probably due to their position, as doctors and well educated persons, rather than ideology, since both were not interested in politics. Like all the Italian Jews, both were very patriotic, Nino for example was proud to have fought in War World I, and he considered himself, like Lucia wholly Italian, in fact, although he died in Tangier, he asked to be buried in Turin, in his homeland, and, Lucia, the same.

From 1930 until 1938, Lucia had a comfortable life, and, she considered herself a privileged woman. Especially when it came to take care of the house and of the three daughters. She had plenty of domestics: a maid, a cook, a nanny, a chauffer.

However, as her daughter told me, even though her profession was very important to her and kept her very busy, she always found time for her husband, daughters, members of the family and friends. Like she always found time to have fun and going to balls, opera, bridge etc.

Lucia in fact strongly believed, as she said in her last conference, that:

An intelligent, bright woman should not forego motherhood because of her profession. Motherhood is not only her natural function, but the coronation of her psychological and spiritual personality. I believe it would be a serious loss, not only for the individual woman but for society as well which would miss her contributions. ${ }^{26}$

Nevertheless, in 1938, with the promulgation of the Racial Laws, everything changed. The Racial Laws, devastated the life of the Italian Jews, who become second class citizens, without any rights.

The Racial Law reduced the position of the Italian Jews to that of pariahs.

Marriage between Jews and non-Jews was prohibited. Jews were forbidden to enter military service, to own more than 50 hectares (about 130 acres) of land, to own or manage enterprises employing more than 100 persons. They were ejected from the Fascist Party. They were forbidden to have any interest, even as shareholders, in enterprises of importance to national defense, they were excluded from all positions in the Stock Exchange and in joint-stock bank and insurance companies. They were forbidden to open new business and to employ Christian workers. Only early fascists (before the racial laws of 1938) and the families of those with especially meritorious military records, were exempted from some of these restrictions.

The Badarida lost their job, Lucia's daughters were not allow to study anymore in public schools, they had to return their membership cards to clubs, associations and societies. At that moment, as Lucia wrote in one of her diaries ${ }^{27}$, she felt rejected, lonely and sad.

The racial laws are devastating our lives and that of friends and relatives of the same faith. ${ }^{28}$

For that reasons, she and her husband decided to leave Italy and to immigrate wherever possible. However, was not easy at all, apparently no country was willing to give visa to the Jews, and the choice where to go, were quite limited, because they were looking also for a country that would accept their qualifications as physicians, and, allow them to work.

After many difficulties and failed ${ }^{29}$ plans, Lucia and her family in 1940 ended up in Morocco, in Tangier,

\footnotetext{
${ }^{26}$ Quotation from the unpublished paper that Lucia gave in the early 1990s in a conference organized by NIDO on Women and Medicine in New York Metropolitan area. This paper was given to the author by her daughter Mirella Bedarida Shapiro, in 2011, p. 3.

${ }_{27}$ Lucia wrote several autobiographical diaries, that she sent almost all, to the Archive of Pieve Santo Stefano in Tuscany, Italy, in the late 1990s. Some pages of these diaries were given to the author by Lucia’s daughter Mirella Bedarida Shapiro.

28 Ibid.

29 The family was supposed to get a visa for Ecuador, but at the last minute it was refused.
} 
that was at that time an International Zone, administrated by 7 countries $^{30}$, including Italy, and for that reason no visa and work permits was required.

When she fled to Tangier, Lucia was helped by some Fascists gerarchi (political leaders), who had been patients of her husband, and had great esteem and respect for him.

The fascist gerarchi in fact help the Bedarida to get all the necessary papers and permits to buy all the medical equipment to be sent to Tangier for the clinic that Nino and Lucia were opening. At the beginning, Lucia and Nino went to Tangier alone, on living temporarily their daughters in Italy, with Lucia's mother, Gemma $^{31}$.

At that time living in Tangier, many European Jews, that left their own countries due to the rise of Nazism persecution. There were a lot of doctors, and, as Lucia wrote, it was difficult because there was a lot of competition. Every national group had its own hospital, even if small and modestly equipped.

However, in spite of these difficulties, Lucia and her husband manage to find their own way in their medical career. They opened a small clinic, open to all, included the Arab population that started drifting toward her husband, as he quickly acquired a reputation for being an excellent surgeon, and, also toward her, as a woman doctor, independently at the beginning of her ability.

Thanks to Lucia in fact hundreds of Morocco and Bedouins women, started to go for the first time to see a doctor, thing that they didn't before, because according to the Muslim ethic, was forbidden to the women to expose her nudity to a male (even if doctor) or being unveiled in public. However, Lucia, or mamma Rida how she was called by those woman, gained soon their appreciation and trust, that for this reason were coming to her, even from far away villages, sometime on a donkey' s back, with their husband, just in order to see "the good tubiba".

Due to her good reputation and professionalism, Lucia had different duties and appointed, she was invited to work for the Morocco Health Department for the underprivileged women of the country, she was referent doctor by the Italian General Consulate and school in Tangier, as well the American school. In 1946, she was chosen as Medical Advisor by the legation of the United States of America. In 1957, she became the official doctor of the Oeuvre Secourse Enfance, a French institution that helped European Jewish refugees. Lucia in fact, worked also (as volunteer) for different Jewish center or groups, some legal and some other underground. Like in helping the Israeli Government in his secret operation to fled the Morocco Jews in Israel.

Her duty was to take care of those Jews, to provide them with medical assistance, like it happened with a group of Jewish boys from a poor ghetto of south Morocco, that while were waiting for the opportunity to leave clandestinely Tangier and come to Israel, they got sick from an epidemic of typhus, and Lucia without awakening the suspicion of the Morocco authorities, success to provide a great amount of medicinal that saved their life.

For her undercover work, the Israeli Government, invited Lucia to continue her work in Israel, in offered her a manager position in the Minister of Health, but she refused, because she thought that Morocco, or better, the people there, in particular the women, needs her mostly.

Lucia in fact, always spoke about Morocco, not only as the land that she saved her, but, foremost the land

\footnotetext{
30 The countries were: England, France, Italy, Spain, Portugal, Belgium and Holland.

${ }^{31}$ Lucia a few months later went back to Italy, in order to bring back her whole family to Tangier. However, Lucia's mother, Gemma, and, grandmother Ninetta, they didn't want to go with Lucia preferring to stay in Italy. This was the last time that Lucia saw her mother and grandmother, because both of them were deported and gassed in June 1944 at their arrival to Auschwitz.
} 
where she could pursue what she loved most: being a Jewish female doctor in an Arab country (in the means of an unprivileged country).

I worked very hard trying to fulfill all my duties and responsibilities. I can proudly say, however, that I never considered the field of medicine as a money making proposition to become wealthy, but as a learning experience to expand my knowledge and increase my capacities to be able to cure those who sleeked my help. I don't recall having ever refused to come to a patient's bedside, no matter what the weather, or the distance was, night or day. ${ }^{32}$

Like she did in helping the delivery of a baby in the middle of the night of a Sussi (ethnic minority) woman, after that she had an orthopedic surgery, and used the crutches to walk. Or, in helping the wife of the German Consol that she was very ill, even after knowing that the Consulate had the names of all the Jews living in Tangier with the intention of deport them to Germany, and, it was, only thanks to the American Alley that arrived in Casablanca that they didn't succeeded.

But as Lucia used to say "a doctor can never refuse to help a sick person, even if this one his responsible of terrible things".

In 1965, Lucia's husband died, and Lucia found herself alone, because her three daughters were living since 1946 in the United States, but she refused to leave Tangier or to move to Italy, where her brothers were living. She thought that she was too old to start a new life, but, mostly, she didn't want to leave the city that welcomes her, where she has many friends and the life that she loved.

Beside her activity as doctor, Lucia was also a researcher. She wrote and published many articles, including a proposal for the establishment of an international university in Tangier, and essay on Dante and medicine, and a study of ancient Arab medicine and its influence on the modern medical mind.

Lucia, in fact, how she wrote in her book The Ancient Arab Medicine and Its Influence on Modern Medical Thought, published in 1967, believed that:

Was extremely helpful to highlight the points of contact between East and West which could being closer these two world that we tend to consider separate and distinct from the view point of thought and scientific development...While, the history of the medicine shows us, as any history does, that in all the manifestation of human thought, there never is a clean out, but a continuity, an evolution, a reciprocal influence... ${ }^{33}$

Lucia lived in Tangier, until the age of 81, when, after a few incidents and healthy problems, she decided to retire and move to the United States, where the three daughters were living. But she never really liked it lived there.

The change was too radical for her, new language, culture, different climate, but above not independence. Nevertheless, even for far away, Lucia stayed in touch with all her friends in Tangier and in the rest of the world. She went to visit them often, she wrote them letter, and, she made a point to have a huge celebration for her 100 years birthday, to which she invited almost everybody she had met in her life and who were still alive. Friends and family come from all over the world to the party she organized by herself in Ancona, her birthplace.

Lucia loved to fly, and, already in her youth, when planes were still quite primitive, she flew several times in small propeller planes. She went hang-gliding in the Italian Alps at 97 and again at 105.

\footnotetext{
${ }^{32}$ Quotation from the unpublished paper that Lucia gave in the early 1990s in a conference organized by NIDO on Women and Medicine in New York Metropolitan area. This paper was given to the author by her daughter Mirella Bedarida Shapiro, in 2011,

p.
33 In Fincato Olivia and D’Agostin Renato, Un giorno con Lucia (A Day with Lucia ), p. 39.
} 
As Mirella, Lucia's daughter said to me, during her life her mother she experienced very traumatic events: the racial discrimination, the dead of her mother and grandmother in Auschwitz, the dead of her husband and of her four young brothers, the suicide on one of her favorite grandsons, and the illness and death of friends and family members. However, each time, she succeeded in overcoming her sorrow, she had the strength to regain again courage and to continue to lovingly care for her family and patients, and, this because her love of life always won out.

Because, as Lucia wrote: "we need to have faith in life-life is stronger than death.,"34

\section{References}

Bedarida, G. (1949). Ebrei d’ Italia. Leghorn: Tirrena.

Bedarida Servadio, L. (2002). "Reflection on an Italian Jewish life", the most ancient of minorities-The Jews of Italy. Westport: Greenwood Press.

Bedarida Servadio, L. (1990). Women and medicine in New York metropolitan area (Unpublished paper, Private Archive of Mirella Bedarida Shapiro).

Bedarida Servadio, L. Unpublished letter to Gemma Barzilai (Private Archive of Mirella Bedarida Shapiro). The letter was given to the author in 2011.

Bettin, C. (2016). A question of identities: Jewish Italian immigrants in New York during and after War World II. Cultural and Religious Studies, 4, 4.

Bettin, C. (2010). Italian Jews from emancipation to racial laws. New York: Palgrave Macmillan.

Fincato, O., \& D’Agostin, R. (2007). Un giorno con Lucia. Italy: Zeropuntozerozero.

Jewish Telegraphic Agency Archive. (2000). Around the Jewish world. Women's life mirror century of struggles success. Retrieved from WWW.JTA.ORG/2000/07/24,1

Stille, A. (2005). The double bind of Italian Jews: Acceptance and assimilation. In Jews in Italy under Fascist and Nazi Rule 1922-1945. New York: Cambridge University Press.

34 See (July 24, 2000) Around the Jewish World: Woman's Life Mirrors Century of Struggles Successes, from www.jta.org/2000/07/24, JTA archive, 1. 